BMJ Open

Diabetes

Research

\& Care

\title{
Is diabetes prevalence higher among HIV-infected individuals compared with the general population? Evidence from MMP and NHANES 2009-2010
}

\author{
Alfonso C Hernandez-Romieu, ${ }^{1}$ Shikha Garg, ${ }^{2,3}$ Eli S Rosenberg, ${ }^{1}$ \\ Angela M Thompson-Paul, ${ }^{4}$ Jacek Skarbinski ${ }^{2,3}$
}

To cite: HernandezRomieu AC, Garg S, Rosenberg ES, et al. Is diabetes prevalence higher among HIV-infected individuals compared with the general population? Evidence from MMP and NHANES 2009-2010. BMJ Open Diabetes Research and Care 2017;5:e000304. doi:10.1136/bmjdrc-2016000304

Received 26 July 2016 Revised 18 October 2016 Accepted 23 November 2016

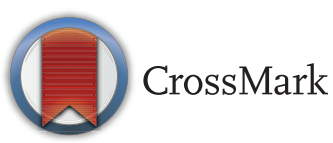

\section{${ }^{1}$ Department of}

Epidemiology, Rollins School of Public Health, Emory University, Atlanta, Georgia, USA

${ }^{2}$ Division of HIV/AIDS

Prevention, National Center for HIV/AIDS, Viral Hepatitis, STD, and TB Prevention, Atlanta, Georgia, USA ${ }^{3}$ Centers for Disease Control and Prevention, Atlanta, Georgia, USA

${ }^{4}$ Division of Heart Disease and Stroke Prevention, Centers for Disease Control and Prevention, Atlanta, Georgia, USA

Correspondence to Dr Alfonso C HernandezRomieu; alfonso.claudio. hernandez@emory.edu

\section{ABSTRACT}

Background: Nationally representative estimates of diabetes mellitus (DM) prevalence among HIV-infected adults in the USA are lacking, and whether HIVinfected adults are at increased risk of DM compared with the general adult population remains controversial. Methods: We used nationally representative survey (2009-2010) data from the Medical Monitoring Project ( $\mathrm{n}=8610$ HIV-infected adults) and the National Health and Nutrition Examination Survey ( $\mathrm{n}=5604$ general population adults) and fit logistic regression models to determine and compare weighted prevalences of DM between the two populations, and examine factors associated with DM among HIV-infected adults.

Results: DM prevalence among HIV-infected adults was $10.3 \%(95 \% \mathrm{Cl} 9.2 \%$ to $11.5 \%)$. DM prevalence was $3.8 \%$ (Cl $1.8 \%$ to $5.8 \%$ ) higher in HIV-infected adults compared with general population adults. HIV-infected subgroups, including women (prevalence difference $5.0 \%, \mathrm{Cl} 2.3 \%$ to $7.7 \%$ ), individuals aged 20-44 (4.1\%, Cl 2.7\% to 5.5\%), and non-obese individuals $(3.5 \%, \mathrm{Cl} 1.4 \%$ to $5.6 \%)$, had increased DM prevalence compared with general population adults. Factors associated with DM among HIV-infected adults included age, duration of HIV infection, geometric mean CD4 cell count, and obesity.

Conclusions: 1 in 10 HIV-infected adults receiving medical care had DM. Although obesity contributes to DM risk among HIV-infected adults, comparisons to the general adult population suggest that DM among HIV-infected persons may develop at earlier ages and in the absence of obesity.

\section{INTRODUCTION}

Diabetes mellitus (DM) is an important cause of morbidity and mortality in the USA. In 2014, there were an estimated 29.1 million persons with DM, of whom $27.8 \%$ were undiagnosed. ${ }^{1}$ Uncontrolled DM can result in significant disability due to complications such as blindness and end-stage renal disease, and is associated with premature mortality due to cancer and vascular disease. $^{2} 3$ Furthermore, the medical and societal costs of DM are substantial. In 2012,

\section{Key messages}

Among a nationally representative US sample of HIV-infected adults receiving medical care, the prevalence of diagnosed diabetes mellitus (DM) was $10.3 \%$.

- HIV-infected adults may be likely to have DM at younger ages and in the absence of obesity compared with the general US adult population.

- The prevalence of DM among HIV-infected adults is high and HIV-care providers should follow existing screening guidelines, which recommend FBG and $\mathrm{HbA1c}$ be obtained prior to and after starting antiretroviral therapy.

in the USA alone, DM accounted for $\$ 176$ billion US in direct medical costs and $\$ 69$ billion US in reduced productivity. ${ }^{4}$

In the USA, advances in treatment of HIV infection have led to decreased mortality and increased life expectancy among HIV-infected persons. ${ }^{5}{ }^{6}$ Consequently, chronic metabolic and cardiovascular diseases such as DM are gaining importance as causes of morbidity and mortality among HIV-infected persons. ${ }^{7}$ While the burden of DM among the general US adult population has been well described, nationally representative estimates of DM prevalence among HIV-infected adults are lacking. In addition, whether HIV-infected adults are at increased risk of developing DM compared with the general adult population remains controversial. ${ }^{8-11}$

We analyzed nationally representative data from the Medical Monitoring Project (MMP) with the following objectives: (1) estimate DM prevalence among a nationally representative sample of HIV-infected adults; (2) compare the prevalence of DM in HIV-infected adults versus the general US adult population; and (3) identify factors associated with prevalent DM among HIV-infected adults. 


\section{METHODS}

\section{Data sources and study design}

We used 2009-2010 data from MMP and the National Health and Nutrition Examination Survey (NHANES) to estimate DM prevalence among HIV-infected adults and the general US adult population, respectively. Our analyses were restricted to adults aged $\geq 20$ years, and excluded pregnant women.

MMP is a surveillance system that produces nationally representative estimates of behavioral and clinical characteristics of HIV-infected adults who receive HIV medical care in the USA. MMP is a cross-sectional survey with a multistage probability design. Detailed descriptions of the sampling methodology and data collection procedures have been published elsewhere. ${ }^{12}$ Briefly, sampling was conducted in three consecutive stages: (1) USA and dependent areas, (2) outpatient HIV care facilities, and (3) HIV-infected adults aged $\geq 18$ years who made at least one medical care visit to a sampled facility between January and April of 2009 and 2010. Data were collected during June 2009 through May 2011. Facility response rates were $76 \%$ $(461 / 603)$ in 2009 and $81 \%(474 / 582)$ in 2010. Approximately $50 \%$ of persons sampled from these facilities completed an interview and had their medical records abstracted. After excluding 81 individuals who were either $<20$ years of age or pregnant, our MMP sample included 8610 participants, representing an estimated average of 427928 HIV-infected adults. The Centers for Disease Control and Prevention (CDC) National Center for HIV, Viral Hepatitis, STD, and TB Prevention has determined MMP to be a non-research public health surveillance activity, and thus, it was not reviewed by a federal institutional review board (IRB). Participating states or territories and facilities obtained local IRB approval to conduct MMP if required locally. Informed consent was obtained from all interviewed participants.

NHANES is a cross-sectional health examination survey with a stratified multistage probability design representative of the general non-institutionalized US population. Descriptions of the sampling plan, and examination and interview protocol are published elsewhere. ${ }^{13}$ In the 20092010 cycle of NHANES, the unweighted response rate for the interviewed and examined persons was $77.3 \%$, resulting in a final sample of 10253 persons. After excluding individuals $<20$ years and pregnant women, 5604 (54.6\%) adults remained in the sample, representing an estimated 2.1 million non-institutionalized adults living in the USA in 2009-2010. NHANES was approved by CDC's National Center for Health Statistics Institutional Research Ethics Review Board.

Survey sample weights in NHANES and MMP account for the differential probabilities of selection, nonresponse to survey instruments, and differences between the final sample and the total population.

\section{Measures}

The primary outcome variable was DM. In MMP, DM was defined using the following criteria documented in the medical record: (1) physician-diagnosed DM listed on a problem list or in the assessment/plan portion of a progress note; or (2) prescription of insulin or oral hypoglycemic medications (excluding metformin monotherapy). In NHANES, DM was defined using the following criteria: (1) answered 'Yes' to the question: 'Other than during pregnancy, have you ever been told by a doctor or health professional that you have diabetes or sugar diabetes?'; or (2) answered 'Yes' to any of the following questions: (a) 'Are you now taking insulin?'; or (b) 'Are you now taking diabetic pills to lower your blood sugar? These are sometimes called oral agents and oral hypoglycemic agents'. Prescription medication data available in NHANES were used to exclude individuals treated with metformin monotherapy who had responded 'Yes' to question 2b. Exclusion of patients on metformin monotherapy who were not classified as having DM in MMP or answered 'No' to question 1 in NHANES were excluded due to the use of this medication for pre-diabetes and polycystic ovarian syndrome. Laboratory criteria to establish the diagnosis of DM were available for MMP and NHANES; however, they were not used because the fasting nature of blood glucose measurements from laboratory data abstracted from medical charts was unknown, and HbAlc measurements have not been validated for the diagnosis of DM among HIV-infected individuals. ${ }^{10} 14 \quad 15$ Our analyses of DM prevalence were therefore restricted to comparisons of diagnosed DM, as described above.

Sociodemographic variables collected for MMP and NHANES included age, sex at birth, race/ethnicity, education, and poverty level. The number and percentage of participants meeting current poverty guidelines for MMP and NHANES were determined using the US Department of Health and Human Services poverty guidelines. In MMP, body mass index (BMI) measurements were abstracted from medical records for the year prior to the interview. If height was missing $(\mathrm{n}=1534$ $(17.7 \%)$ in MMP), BMI category was inferred from recorded weight using previously published methods. ${ }^{16}$ In NHANES, BMI was measured using standardized techniques and equipment. BMI $\geq 30 \mathrm{~kg} / \mathrm{m}^{2}$ was considered indicative of obesity. Clinical MMP variables included time since HIV diagnosis, geometric mean CD4+ T-lymphocyte (CD4) count, documented prescription of antiretroviral therapy (ART), and disease stage per CDC criteria. ${ }^{17}$

CD4 were described using geometric means, calculated by back transforming the logarithm of CD4; geometric means instead of arithmetic means were used because of the skewed distribution of CD4. MMP participants were classified as being infected with hepatitis $\mathrm{C}$ virus (HCV) if any of the following were documented in their medical record: (1) a positive anti-HCV enzyme immunoassay (EIA) or strip immunoblot assay (RIBA); (2) an HCV genotype or (3) HCV-RNA identified through reverse transcriptase-PCR (RT-PCR). ${ }^{18}$ Indeterminate results of EIA/RIBA, HCV genotype, or 
HCV-RNA were considered negative. All NHANES participants received a screening HCV antibody test by EIA with confirmation of positive test results using RIBA. Samples with an indeterminate RIBA were tested for HCV-RNA to confirm HCV infection status.

\section{Data analyses}

Prevalence of and factors associated with DM among HIV-infected adults

Among HIV-infected adults, we calculated the weighted prevalence and 95\% CIs of DM overall and by each of the following characteristics: age (20-44, 45-60, and $\geq 60$ years), sex at birth, race/ethnicity (non-Hispanic White and Black, Hispanic, and Other), education (less than high school, high school or equivalent, and more than high school), poverty level (living at or below the poverty line and living above the poverty line, obesity, time since HIV diagnosis $(<5,5-9$, and $\geq 10$ years $)$, geometric mean CD4 count (0-199, 200-349, 350-499, and $\geq 500$ cells $/ \mathrm{mm}^{3}$ ), use of ART during the surveillance period, CDC HIV disease stage (AIDS or nadir CD4 0-199, no AIDS and nadir CD4 200-500, and no AIDS and nadir CD4>500), and HCV coinfection. All characteristics were analyzed as categorical variables.

To identify factors associated with DM in HIV-infected persons, we used multivariable logistic regression models with $\mathrm{DM}$ as the dependent variable, and all previously mentioned characteristics as independent variables. We computed model-adjusted prevalences for all levels of each of the selected characteristics with predicted marginal means, and estimated crude and adjusted prevalence ratios (PR) for each characteristic. ${ }^{19}{ }^{20}$ We calculated CIs for adjusted-prevalence estimates and PRs.

\section{Comparisons between HIV-infected adults receiving medical} care and general US population adults

Weighted percentages and CIs were determined for DM among HIV-infected adults and the general US adult population stratified by age group, sex at birth, race/ethnicity, education, poverty level, obesity, and HCV infection.

We used marginal standardization methods with predicted marginal probabilities to compare the prevalence of DM between MMP and NHANES. In marginal standardization, the predicted probability of the outcome of interest is adjusted to a weighted average reflecting the distribution of covariates in the target population; the marginal effect obtained is the proportion of subjects with the outcome that would have been observed were the study population forced to the exposure level (ie, HIV infection). In other words, given the demographic and clinical characteristics of the populations in MMP and NHANES, what would the predicted probability of DM be were they to be infected with HIV and vice-versa. ${ }^{20}$

Under the assumption that MMP and NHANES were two independent samples, with independent design variables and weights, we combined the two data sets and constructed a multivariable logistic model using predicted marginal probabilities with DM as the outcome variable and the following independent variables: an indicator variable for survey type ( $1=\mathrm{MMP}$; $0=\mathrm{NHANES})$, all characteristics listed above, and interaction terms between the indicator variable and all characteristics. ${ }^{21} 22$

Using the predicted marginal prevalence of DM, we computed prevalence differences (PD) comparing the two populations, adjusting for all characteristics in MMP and NHANES included in the model. ${ }^{19}$ Linear contrasts were used to test for heterogeneity among subgroups between the adjusted estimates of diagnosed DM in the HIV-infected and general US adult populations. To assess whether differences in care-seeking could account for differences in DM prevalence between the two populations, we performed a second analysis restricting our comparison of HIV-infected adults receiving medical care to the general US adult population who had received medical care in the previous year.

All analyses were performed using SAS 9.3 (SAS Institute, Cary, North Carolina, USA) and SAS-callable SUDAAN 10.0.1 (RTI International, Research Triangle Park, North Carolina, USA) and accounted for clustering, unequal selection probabilities, and non-response.

\section{RESULTS}

MMP participants had the following characteristics: male (73.6\%), non-Hispanic black (41.3\%), aged 45 or more years $(59.9 \%)$, with greater than a high school education $(52.2 \%)$, and living above the federal poverty level $(56.5 \%)$ (table 1). A quarter of MMP participants had a BMI $\geq 30 \mathrm{~kg} / \mathrm{m}^{2}, 20.6 \%$ were HCV-positive, $90.0 \%$ had been prescribed ART in the previous year, and $73.0 \%$ had their most recent HIV viral load reported $<200$ copies/mL. NHANES participants had the following characteristics: male (49.3\%), non-Hispanic black $(11.7 \%)$, aged 45 or more years $(51.4 \%)$, with greater than a high school education (58.7\%), and living above the federal poverty level $(91.5 \%)$. More than a third $(36.0 \%)$ of the general US adult population had a BMI $\geq 30 \mathrm{~kg} / \mathrm{m}^{2}$, and $1.7 \%$ had HCV infection.

The unadjusted prevalence of DM (CI) among HIV-infected adults was $10.3 \%$ (9.1\% to $11.5 \%$ ), and was higher compared with the general US adult population $(8.3 \%(7.2 \%$ to $9.4 \%))$ as well as the general US adult population having received care in the previous 12 months $(9.7 \%$ (8.4\% to $11.1 \%)$ ) (data not shown). Among HIV-infected adults with diagnosed DM, 3.9\% (95\% CI $2.9 \%$ to $5.2 \%$ ) had DM type 1, 52.3\% (CI $46.7 \%$ to $57.8 \%$ ) had DM type 2, and $43.9 \%$ (CI $38.1 \%$ to $49.8 \%$ ) had unspecified DM. After adjusting for differences in distributions of sex, age, race/ethnicity, education, poverty, obesity, and HCV infection prevalence, the adjusted PD (aPD) of DM in HIV-infected adults versus the general US adult population was 3.8\% (table 2). The largest difference in DM prevalence among HIV-infected adults relative to their counterparts 
Table 1 Characteristics of HIV-infected adults and general US population adults, MMP and NHANES 2009-2010

\begin{tabular}{|c|c|c|c|c|}
\hline & \multicolumn{2}{|c|}{ HIV-infected adults* } & \multicolumn{2}{|c|}{ General population adults* } \\
\hline & Sample $\mathbf{n}$ & Weighted \% (95\% Cl) & Sample n & Weighted \% (95\% Cl) \\
\hline Total & 8610 & - & 5604 & - \\
\hline \multicolumn{5}{|l|}{ Sex at birth } \\
\hline Male & 6349 & 73.6 (70.3 to 76.7$)$ & 2745 & 49.3 (48.1 to 50.6$)$ \\
\hline Female & 2261 & 26.4 (23.3 to 29.7$)$ & 2859 & 50.7 (49.4 to 51.9$)$ \\
\hline \multicolumn{5}{|l|}{ Race/ethnicity } \\
\hline White (non-Hispanic) & 2869 & 34.6 (27.6 to 42.3$)$ & 2584 & 67.3 (59.8 to 74.0$)$ \\
\hline Black (non-Hispanic) & 3512 & 41.3 (32.4 to 50.8$)$ & 1051 & $11.7(10.0$ to 13.7$)$ \\
\hline Hispanic or Latino & 1827 & 19.3 (14.2 to 25.7$)$ & 1656 & 14.0 (8.8 to 21.3$)$ \\
\hline Other & 402 & 4.9 (3.9 to 6.0$)$ & 313 & 7.1 (5.1 to 9.9$)$ \\
\hline \multicolumn{5}{|l|}{ Age in years } \\
\hline $20-44$ & 3412 & 40.1 (38.7 to 41.5$)$ & 2518 & $48.6(46.2$ to 51.1$)$ \\
\hline $45-60$ & 4366 & 50.3 (48.9 to 51.6$)$ & 1473 & $29.8(28.5$ to 31.1$)$ \\
\hline$\geq 60$ & 832 & 9.6 (8.8 to 10.6$)$ & 1613 & 21.6 (20.1 to 23.2$)$ \\
\hline \multicolumn{5}{|l|}{ Education } \\
\hline Less than high school & 1937 & $21.5(19.1$ to 24.1$)$ & 1570 & $18.4(16.5$ to 20.5$)$ \\
\hline High school or equivalent & 2314 & $26.3(24.1$ to 28.7$)$ & 1289 & 22.9 (20.7 to 25.2$)$ \\
\hline More than high school & 4356 & $52.2(47.7$ to 56.6$)$ & 2722 & 58.7 (55.7 to 61.7$)$ \\
\hline \multicolumn{5}{|l|}{ Living at or below poverty line } \\
\hline Yes & 3790 & 43.5 (39.6 to 47.5$)$ & 713 & 8.5 (7.0 to 10.3$)$ \\
\hline No & 4565 & 56.5 (52.5 to 60.4$)$ & 4608 & 91.5 (89.7 to 93.0$)$ \\
\hline \multicolumn{5}{|l|}{ Obese $\left(\mathrm{BMI} \geq 30 \mathrm{~kg} / \mathrm{m}^{2}\right)$} \\
\hline Yes & 2071 & 25.5 (23.9 to 27.2$)$ & 2073 & 36.0 (34.0 to 38.2$)$ \\
\hline No & 6208 & 74.5 (72.8 to 76.2$)$ & 3291 & 64.0 (61.9 to 66.0$)$ \\
\hline \multicolumn{5}{|l|}{ Hepatitis C virus $\ddagger$} \\
\hline Positive & 1556 & 20.6 (18.7 to 22.7$)$ & 106 & 1.7 (1.2 to 2.4$)$ \\
\hline Negative & 5590 & 79.4 (77.3 to 81.3$)$ & 5190 & 98.3 (97.6 to 98.8$)$ \\
\hline \multicolumn{5}{|l|}{ Time since HIV diagnosis } \\
\hline Less than 5 years & 1866 & $22.4(20.7$ to 24.1$)$ & - & - \\
\hline $5-9$ years & 1932 & 22.6 (21.6 to 23.6$)$ & - & - \\
\hline 10 or more years & 4806 & 55.0 (52.8 to 57.3$)$ & - & - \\
\hline \multicolumn{5}{|l|}{ AIDS/nadir CD4 count in cells $/ \mathrm{mm}^{3}$} \\
\hline AIDS or nadir CD4 0-199 & 5952 & $68.5(67.2$ to 69.7$)$ & - & - \\
\hline No AIDS and nadir CD4 200-500 & 2098 & 24.8 (23.4 to 26.2$)$ & - & - \\
\hline No AIDS and nadir CD4 >500 & 540 & $6.8(6.0$ to 7.6$)$ & - & - \\
\hline \multicolumn{5}{|l|}{ Geometric mean CD4 past 12 months } \\
\hline 0-199 cells $/ \mathrm{mm}^{3}$ & 1118 & $13.0(12.1$ to 13.9$)$ & - & - \\
\hline 200-349 cells $/ \mathrm{mm}^{3}$ & 1486 & $17.9(16.9$ to 19.1$)$ & - & - \\
\hline 350-499 cells $/ \mathrm{mm}^{3}$ & 1949 & 23.6 (22.6 to 24.7$)$ & - & - \\
\hline$\geq 500$ cells $/ \mathrm{mm}^{3}$ & 3739 & 45.5 (44.0 to 47.0$)$ & - & - \\
\hline \multicolumn{5}{|l|}{ Prescribed ART } \\
\hline Yes & 7751 & $90.0(89.2$ to 90.7$)$ & - & - \\
\hline No & 828 & 10.1 (9.3 to 10.8$)$ & - & - \\
\hline \multicolumn{5}{|c|}{ Most recent viral load undetectable or $<200$ copies $/ \mathrm{mL}$} \\
\hline Yes & 6287 & $73.0(71.0$ to 75.0$)$ & - & - \\
\hline No & 2323 & $27.0(25.1$ to 29.1$)$ & - & - \\
\hline
\end{tabular}

*Includes adults $\geq 20$ years of age and excludes pregnant women.

†Calculated using the ratio of annual household income to number of people in the household.

$\ddagger A$ total of $n=7146$ and $n=5295$ were screened for hepatitis $C(H C V)$ in MMP and NHANES, respectively. HCV positivity was defined as having a documented positive anti-HCV enzyme immunoassay or strip immunoblot assay RIBA, HCV genotype, or HCV RNA through reverse transcriptase-PCR (RT-PCR).

ART, antiretroviral therapy; BMI, body mass index; MMP, Medical Monitoring Project; NHANES, National Health and Nutrition Examination Survey.

in the general US adult population occurred among those with HCV infection (6.3\%), those with a high school or equivalent education $(5.1 \%)$, women $(5.0 \%)$, non-Hispanics whites $(4.9 \%)$, individuals living at or below the poverty line $(4.6 \%)$, obese individuals $(4.4 \%)$ and ages 20-44 years (4.1\%). After restricting the NHANES population to adults who had received care in the previous 12 months, associations were similar to those described above with a slight decrease in the magnitude of DM PD (table 3). 
Table 2 Predicted marginal prevalence and prevalence comparisons of diagnosed diabetes among HIV-infected adults and general US population adults, MMP and NHANES 2009, 2010

\begin{tabular}{|c|c|c|c|c|c|}
\hline & $\begin{array}{l}\text { HIV-infected adults } \\
\text { Adjusted prevalence }(95 \% \mathrm{Cl})\end{array}$ & $\begin{array}{l}\text { General population adults } \\
\text { Adjusted prevalence }(95 \% \mathrm{Cl})\end{array}$ & aPR $(95 \% \mathrm{Cl})^{*}$ & aPD $(95 \% \mathrm{Cl}) \dagger$ & p Value \\
\hline Total & $11.8(10.1$ to 13.7$)$ & $8.0(7.1$ to 9.1$)$ & $1.47(1.21$ to 1.78$)$ & $3.8(1.8$ to 5.8$)$ & 0.0002 \\
\hline \multicolumn{6}{|l|}{ Sex at birth } \\
\hline Male & 11.2 (9.9 to 12.7$)$ & $8.9(7.2$ to 10.7$)$ & $1.28(1.02$ to 1.60$)$ & $2.4(0.3$ to 4.6$)$ & 0.03 \\
\hline Female & 12.4 (10.1 to 15.2$)$ & 7.4 (6.4 to 8.5$)$ & $1.68(1.31$ to 2.15$)$ & 5.0 (2.3 to 7.7$)$ & 0.0003 \\
\hline \multicolumn{6}{|l|}{ Race/ethnicity } \\
\hline White (non-Hispanic) & 11.4 (9.6 to 13.5$)$ & 6.5 (5.3 to 7.9$)$ & 1.76 (1.37 to 2.28$)$ & 4.9 (2.7 to 7.2$)$ & $<0.0001$ \\
\hline Black (non-Hispanic) & 13.1 (11.1 to 15.4$)$ & $11.8(9.7$ to 14.3$)$ & 1.11 (0.87 to 1.42$)$ & $1.3(-1.7$ to 4.3$)$ & 0.4 \\
\hline Hispanic or Latino & 13.1 (10.3 to 16.4$)$ & $11.4(9.4$ to 13.8$)$ & $1.14(0.85$ to 1.54$)$ & $1.6(-2.1$ to 5.4$)$ & 0.4 \\
\hline Other & $11.7(8.5$ to 15.9$)$ & $14.8(11.4$ to 18.9$)$ & $0.79(0.53$ to 1.17$)$ & $-3.1(-8.3$ to 2.1$)$ & 0.2 \\
\hline \multicolumn{6}{|l|}{ Age in years } \\
\hline $20-44$ & $6.4(5.3$ to 7.6$)$ & 2.3 (1.7 to 3.2 ) & 2.77 (1.91 to 4.02 ) & 4.1 (2.7 to 5.5$)$ & $<0.0001$ \\
\hline $45-60$ & 13.0 (11.0 to 15.2$)$ & 9.1 (7.5 to 10.9$)$ & $1.43(1.12$ to 1.81$)$ & 3.9 (1.3 to 6.5$)$ & 0.004 \\
\hline$\geq 60$ & 21.9 (17.9 to 26.6$)$ & 19.5 (16.8 to 22.6$)$ & $1.12(0.88$ to 1.44$)$ & $2.4(-2.8$ to 7.6$)$ & 0.4 \\
\hline \multicolumn{6}{|l|}{ Education } \\
\hline Less than high school & $13.0(10.3$ to 16.2$)$ & 10.6 (9.3 to 12.1$)$ & $1.22(0.94$ to 1.59$)$ & $2.3(-0.9$ to 5.6$)$ & 0.2 \\
\hline High school or equivalent & 11.4 (9.9 to 13.6$)$ & $6.3(5.3$ to 7.5$)$ & 1.81 (1.39 to 2.35$)$ & 5.1 (2.6 to 7.5$)$ & 0.0001 \\
\hline More than high school & 11.6 (9.9 to 13.6$)$ & 7.8 (6.5 to 9.4$)$ & $1.48(1.17$ to 1.87$)$ & $3.8(1.5$ to 6.1$)$ & 0.001 \\
\hline \multicolumn{6}{|l|}{ Living at or below poverty lineł } \\
\hline No & $11.8(10.1$ to 13.8$)$ & 8.1 (7.2 to 9.1$)$ & $1.46(1.20$ to 1.77$)$ & $3.7(1.6$ to 5.8$)$ & 0.0005 \\
\hline Yes & $11.8(9.8$ to 14.1$)$ & 7.2 (5.4 to 9.7$)$ & $1.63(1.17$ to 2.27$)$ & 4.6 (1.7 to 7.4$)$ & 0.002 \\
\hline \multicolumn{6}{|l|}{ Obesity (BMI $\geq 30 \mathrm{~kg} / \mathrm{m}^{2}$ ) } \\
\hline No & $7.8(6.2$ to 9.9$)$ & 4.3 (3.5 to 5.4$)$ & 1.81 (1.32 to 2.49$)$ & 3.5 (1.4 to 5.6$)$ & 0.0009 \\
\hline Yes & 18.1 (15.8 to 20.7$)$ & $13.7(12.1$ to 15.6$)$ & $1.32(1.10$ to 1.58$)$ & 4.4 (1.5 to 7.4$)$ & 0.003 \\
\hline \multicolumn{6}{|l|}{ Hepatitis C virus $\S$} \\
\hline Positive & 13.4 (11.0 to 16.2$)$ & 7.1 (3.8 to 13.1$)$ & $1.88(0.98$ to 3.61$)$ & $6.3(1.1$ to 11.4$)$ & 0.02 \\
\hline Negative & $11.8(10.1$ to 13.7$)$ & 8.1 (7.1 to 9.1$)$ & $1.46(1.21$ to 1.77$)$ & $3.7(1.7$ to 5.7$)$ & 0.0003 \\
\hline
\end{tabular}

${ }^{*}$ Prevalence ratio using NHANES as the referent category.

†Prevalence difference calculated as prevalence(MMP)-prevalence(NHANES).

$¥$ Calculated using the ratio of annual household income to number of people in the household.

$\S A$ total of $n=7146$ and $n=5295$ were screened for hepatitis $C$ (HCV) in MMP and NHANES, respectively. HCV positivity was defined as having a documented positive anti-HCV enzyme

immunoassay or strip immunoblot assay RIBA, HCV genotype, or HCV RNA through reverse transcriptase-PCR (RT-PCR).

aPD, adjusted prevalence difference; aPR, adjusted prevalence ratio; BMI, body mass index; MMP, Medical Monitoring Project; NHANES, National Health and Nutrition Examination Survey. 


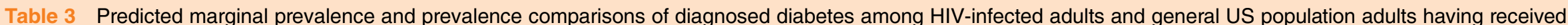
medical care in the previous 12 months, MMP and NHANES 2009-2010

\begin{tabular}{|c|c|c|c|c|c|}
\hline & $\begin{array}{l}\text { HIV-infected adults } \\
\text { Adjusted prevalence }(95 \% \mathrm{Cl})\end{array}$ & $\begin{array}{l}\text { General population adults } \\
\text { Adjusted prevalence }(95 \% \mathrm{Cl})\end{array}$ & $\operatorname{aPR}(95 \% \mathrm{Cl})^{\star}$ & aPD (95\% Cl)† & p Value \\
\hline Total & $12.4(10.6$ to 14.4$)$ & 9.38 (8.2 to 10.7$)$ & $1.32(1.09$ to 1.61$)$ & $3.0(0.8$ to 5.2$)$ & 0.007 \\
\hline \multicolumn{6}{|l|}{ Sex at birth } \\
\hline Male & 11.7 (10.3 to 13.3$)$ & 10.6 (8.6 to 13$)$ & $1.11(0.88$ to 1.4$)$ & $1.1(-1.4$ to 3.7$)$ & 0.4 \\
\hline Female & $13.0(10.5$ to 15.9$)$ & 8.36 (7.3 to 9.6$)$ & 1.55 (1.22 to 1.97$)$ & $4.6(1.7$ to 7.5$)$ & 0.002 \\
\hline \multicolumn{6}{|l|}{ Race/ethnicity } \\
\hline White (non-Hispanic) & $12.0(10.1$ to 14.2$)$ & 7.58 (6.2 to 9.2$)$ & 1.58 (1.23 to 2.04$)$ & 4.4 (1.9 to 6.9$)$ & 0.0005 \\
\hline Black (non-Hispanic) & 13.8 (11.7 to 16.2$)$ & $13.47(11.3$ to 15.9$)$ & $1.02(0.81$ to 1.29$)$ & $0.3(-2.8$ to 3.4$)$ & 0.8 \\
\hline Hispanic or Latino & 13.8 (10.9 to 17.3$)$ & 14 (11.6 to 16.7$)$ & $0.98(0.73$ to 1.31$)$ & $-0.3(-4.3$ to 3.8$)$ & 0.9 \\
\hline Other & $12.3(8.9$ to 16.7$)$ & $17.22(13.3$ to 22$)$ & 0.71 (0.48 to 1.06$)$ & $-4.9(-11.0$ to 0.8$)$ & 0.09 \\
\hline \multicolumn{6}{|l|}{ Age in years } \\
\hline $20-44$ & 6.5 (5.4 to 7.8$)$ & 2.72 (1.9 to 3.9$)$ & 2.37 (1.59 to 3.54$)$ & 3.7 (2.2 to 5.3$)$ & $<0.0001$ \\
\hline $45-60$ & $13.1(11.1$ to 15.4$)$ & 10.35 (8.6 to 12.4$)$ & $1.27(1.00$ to 1.61$)$ & $2.8(-0.0$ to 5.6$)$ & 0.05 \\
\hline$\geq 60$ & $22.2(18.1$ to 26.9$)$ & $20.54(17.8$ to 23.6$)$ & 1.08 (0.85 to 1.37$)$ & $1.6(-3.6$ to 6.9$)$ & 0.5 \\
\hline \multicolumn{6}{|l|}{ Education } \\
\hline Less than high school & $13.6(10.8$ to 17$)$ & $13.12(11.3$ to 15.1$)$ & 1.04 (0.79 to 1.36$)$ & $0.5(-3.2$ to 4.2$)$ & 0.8 \\
\hline High school or equivalent & 11.9 (9.9 to 14.4$)$ & $7.32(6$ to 8.9$)$ & 1.63 (1.23 to 2.15$)$ & 4.6 (1.9 to 7.3$)$ & 0.001 \\
\hline More than high school & $12.2(10.3$ to 14.4$)$ & $8.94(7.4$ to 10.8$)$ & $1.36(1.07$ to 1.74$)$ & $3.3(0.7$ to 5.8$)$ & 0.01 \\
\hline \multicolumn{6}{|l|}{ Living at or below poverty lineł } \\
\hline No & 12.4 (10.6 to 14.5$)$ & $9.43(8.3$ to 10.6$)$ & 1.31 (1.08 to 1.60$)$ & $3.0(0.7$ to 5.2$)$ & 0.01 \\
\hline Yes & $12.4(10.3$ to 14.8$)$ & $8.72(6.6$ to 11.5$)$ & $1.42(1.03$ to 1.95$)$ & $3.6(0.5$ to 6.8$)$ & 0.02 \\
\hline \multicolumn{6}{|l|}{ Obesity (BMI $\geq 30$ kg/m²) } \\
\hline No & 8.1 (6.4 to 10.3$)$ & 5.14 (4.1 to 6.5$)$ & $1.58(1.13$ to 2.21$)$ & $3.0(0.7$ to 5.3$)$ & 0.01 \\
\hline Yes & $18.7(16.2$ to 21.4$)$ & 15.35 (13.5 to 17.4$)$ & 1.22 (1.01 to 1.46$)$ & $3.3(0.2$ to 6.5$)$ & 0.04 \\
\hline \multicolumn{6}{|l|}{ Hepatitis C virus§ } \\
\hline Positive & $14.0(11.5$ to 17$)$ & $8.22(4.4$ to 14.8$)$ & $1.71(0.90$ to 3.23$)$ & $5.8(0.1$ to 11.5$)$ & 0.04 \\
\hline Negative & $12.4(10.6$ to 14.4$)$ & 9.4 (8.3 to 10.7$)$ & $1.32(1.08$ to 1.60$)$ & $3.0(0.8$ to 5.2$)$ & 0.009 \\
\hline
\end{tabular}

\section{*Prevalence ratio using NHANES as the referent category.}

†Prevalence difference calculated as prevalence(MMP)-prevalence(NHANES).

$\neq$ Calculated using the ratio of annual household income to number of people in the household.

$\S A$ total of $n=7146$ and $n=5295$ were screened for hepatitis C (HCV) in MMP and NHANES, respectively. HCV positivity was defined as having a documented positive anti-HCV enzyme immunoassay or strip immunoblot assay RIBA, HCV genotype, or HCV RNA through reverse transcriptase-PCR (RT-PCR).

aPD, adjusted prevalence difference; aPR, adjusted prevalence ratio; BMI, body mass index; MMP, Medical Monitoring Project; NHANES, National Health and Nutrition Examination Survey. 
Among HIV-infected adults, DM prevalence varied by selected characteristics (table 4). The adjusted DM prevalence was lowest among those aged 20-44 years $(6.7 \%)$ and highest among those aged $\geq 60$ years $(19.6 \%)$, and obese $(18.9 \%)$ (table 4). Factors independently associated with total DM among HIV-infected adults included increasing age, obesity, increasing time since HIV diagnosis, and geometric mean CD4.

\section{DISCUSSION}

Among a nationally representative US sample of HIV-infected adults receiving medical care in 2009 and 2010, the DM prevalence was 10.3\%; increasing age, obesity, longer duration of HIV infection, and geometric mean CD4 were independently associated with a higher DM prevalence. When compared with the general US adult population, HIV-infected individuals had a $3.8 \%$ higher prevalence of DM after adjusting for age, sex, race/ethnicity, education, poverty-level, obesity, and HCV infection. This analysis provides the first nationally representative estimate of DM burden among HIV-infected adults and suggests that HIV-infected persons may be more likely to have DM at younger ages and in the absence of obesity compared with the general US adult population.

Our estimates of DM prevalence among HIV-infected adults are lower compared with previous US studies. The Multicenter AIDS Cohort Study reported 14\% DM prevalence among 411 men who have sex with men recruited from 1999 to $2003 .^{8}$ The Veterans Aging Cohort Study Virtual Cohort observed a similar baseline prevalence $(14 \%)$ in a cohort of 27350 HIV-infected veterans recruited from 2003 to $2009 .{ }^{23}$ These differences may reflect the burden of undiagnosed diabetes measured with fasting blood glucose and HbAlc. The HIV Outpatient Study (HOPS) reported a higher DM prevalence among HIV-infected women (19\%) compared with HIV-infected men (12\%), a finding that although not statistically significant was observed in our sample. ${ }^{24}$ Conversely, DM prevalence among HIV-infected individuals in non-US cohorts is significantly lower than our estimate, ranging from $2.7 \%$ to $3.3 \% .^{9} 2526$

Similar to previous studies, we observed a strong association between both increasing age and obesity and prevalent DM among HIV-infected individuals, ${ }^{810} 11242627$ suggesting that these traditional risk factors play a major role in the development of DM among HIV-infected adults. Despite evidence suggesting a link between ART and DM, ART prescription in the past year was not associated with prevalent DM in our study. ${ }^{9} 2426$ This may be due to our inability to assess cumulative exposure to ART in MMP. The ARTs indinavir, zidovudine, saquinavir, stavudine, and didanosine have been associated with a higher prevalence of $\mathrm{DM} ;{ }^{924} 25$ only a small percentage of HIV-infected adults in MMP were currently prescribed these agents $(0.4 \%$ indinavir, $11.2 \%$ zidovudine, $1.0 \%$ saquinavir, $1.2 \%$ stavudine, and $2.4 \%$ didanosine), which may also account for the null association between ART exposure and DM. Time since HIV diagnosis was significantly associated with a higher DM prevalence. Although the exact mechanistic pathways measured by this variable are hard to elucidate, it may serve as a proxy for older age, exposure to chronic inflammation due to HIV infection, as well as cumulative exposure to ART, all of which have been linked to insulin resistance. ${ }^{24}$ 26-30 Another surrogate marker for systemic inflammation, CD4 count nadir, was not associated with increased prevalence of DM after adjusting for other covariates. This is contrary to previous studies which have linked $\mathrm{CD} 4+$ nadir $<200$ cells $/ \mu \mathrm{L}$ with increased levels of interleukin 6 , high-sensitivity $\mathrm{C}$ reactive protein, and soluble tumor necrosis receptors. ${ }^{26} 3132$ In addition, geometric mean $\mathrm{CD} 4$ count was associated with a higher prevalence of DM in our sample; however, the lack of clear directionality makes it hard to interpret. Taken together, our results highlight the need for more nuanced measures of chronic inflammation present in HIV infection and their interaction with traditional risk factors such as obesity.

The aPD of DM between HIV-infected adults and the general US adult population was heterogeneous by subpopulation. HIV-infected women had a 5\% higher prevalence than their counterparts in the general population, an effect that was independent of obesity. There is evidence that the use of ART may increase conversion to DM among women with high-risk genetic polymorphisms; ${ }^{33}$ however, sex-specific differences in insulin resistance, particularly the role of sex hormones in the setting of HIV infection, remain understudied. Beyond the effect of ART on insulin resistance and development of DM, chronic inflammation during HIV infection may accelerate the development of comorbid conditions such as DM. ${ }^{32}$ Although this chronic inflammatory state may explain the development of DM among HIV-infected adults at younger ages and among the nonobese, there is a continued need for research assessing other important risk factors for DM among HIV-infected individuals, including diet and exercise, as well as a deeper understanding of insulin and glucose homeostasis in the setting of HIV infection.

Finally, although HCV has been described as a risk factor for DM in the general population, our findings indicate that HIV may compound the deleterious effects of HCV, putting $\mathrm{HIV} / \mathrm{HCV}$ coinfected individuals at even higher risk of DM. ${ }^{34}$ Observed differences could be due to a lower engagement in medical care by HCV-infected adults in the general population and suboptimal screening practices. ${ }^{35}$ Nevertheless, this finding is particularly relevant, given the availability of directly acting antiviral agents as curative HCV therapy and highlights a potential additional benefit of HCV treatment for coinfected patients. ${ }^{36}$

Based on our findings, as well as current literature regarding DM among HIV-infected individuals, there are several important implications. First, HIV-care 


\begin{tabular}{|c|c|c|c|c|c|c|}
\hline & Sample $n^{*}$ & $\begin{array}{l}\text { Weighted } \\
\text { prevalence \% }(95 \% \mathrm{Cl})\end{array}$ & $\begin{array}{l}\text { Adjusted weighted } \\
\text { prevalence } \%(95 \% \mathrm{Cl})\end{array}$ & cPR (95\% Cl) & aPR $(95 \% \mathrm{Cl})$ & p Value \\
\hline Total & 8610 & $10.2(9.1$ to 11.4$)$ & 10.7 (9.6 to 11.8$)$ & - & - & - \\
\hline Sex at birth & & & & & & 0.2 \\
\hline Male & 6349 & 9.5 (8.3 to 10.7$)$ & $10.3(9.2$ to 11.5$)$ & Ref & Ref & \\
\hline Female & 2261 & $12.4(10.7$ to 14.0$)$ & $11.5(9.7$ to 13.6$)$ & $1.30(1.14$ to 1.49$)$ & $1.12(0.94$ to 1.33$)$ & \\
\hline Race/ethnicity & & & & & & 0.1 \\
\hline White (non-Hispanic) & 2869 & $8.9(7.4$ to 10.5$)$ & $9.4(8.0$ to 10.9$)$ & ref & ref & \\
\hline Black (non-Hispanic) & 3512 & 11.3 (9.9 to 12.7$)$ & 11.5 (10.0 to 13.2$)$ & 1.26 (1.07 to 1.50$)$ & $1.23(1.02$ to 1.48$)$ & \\
\hline Hispanic or Latino & 1827 & 10.4 (8.7 to 12.1$)$ & $11.2(9.3$ to 13.6$)$ & 1.17 (0.93 to 1.46$)$ & $1.20(0.96$ to 1.50$)$ & \\
\hline Other & 402 & $10.3(6.7$ to 13.9$)$ & 10.7 (7.8 to 14.7$)$ & 1.16 (0.87 to 1.53$)$ & 1.15 (0.87 to 1.52$)$ & \\
\hline Age in years & & & & & & $<0.0001$ \\
\hline $20-44$ & 3412 & 5.8 (4.9 to 6.7$)$ & 6.7 (5.8 to 7.7$)$ & ref & ref & \\
\hline $45-60$ & 4366 & $12.0(10.7$ to 13.4$)$ & $11.9(10.5$ to 13.6$)$ & 2.07 (1.82 to 2.36$)$ & 1.79 (1.53 to 2.08$)$ & \\
\hline$\geq 60$ & 832 & 19.3 (16.1 to 22.6$)$ & 19.6 (16.3 to 23.5$)$ & $3.33(2.83$ to 3.91$)$ & 2.94 (2.36 to 3.67$)$ & \\
\hline Education & & & & & & 0.6 \\
\hline Less than high school & 1937 & $12.1(10.1$ to 14.1$)$ & 11.5 (9.7 to 13.6$)$ & $1.24(1.00$ to 1.55$)$ & 1.09 (0.89 to 1.34$)$ & \\
\hline High school or equivalent & 2314 & 9.7 (8.0 to 11.5$)$ & 10.3 (8.6 to 12.2$)$ & $1.00(0.84$ to 1.18$)$ & $0.97(0.80$ to 1.18$)$ & \\
\hline More than high school & 4356 & 9.7 (8.3 to 11.2$)$ & 10.5 (9.3 to 12$)$ & ref & ref & \\
\hline Living at or below poverty lineł & & & & & & 0.9 \\
\hline No & 4565 & 10.4 (8.8 to 11.3$)$ & 10.6 (9.2 to 12.2$)$ & ref & ref & \\
\hline Yes & 3790 & 10.7 (9.1 to 12.2$)$ & $10.8(9.3$ to 12.5$)$ & 1.06 (0.92 to 1.23$)$ & $1.02(0.83$ to 1.25$)$ & \\
\hline Obesity $\left(\mathrm{BMI} \geq 30 \mathrm{~kg} / \mathrm{m}^{2}\right)$ & & & & & & $<0.0001$ \\
\hline No & 6208 & $7.8(6.4$ to 9.1$)$ & $7.9(6.7$ to 9.4$)$ & ref & ref & \\
\hline Yes & 2071 & $17.7(16.4$ to 19.1$)$ & $18.9(17$ to 20.9$)$ & 2.29 (1.88 to 2.79$)$ & 2.38 (1.91 to 2.95$)$ & \\
\hline Hepatitis C virus§ & & & & & & 0.3 \\
\hline Positive & 1556 & $12.9(10.9$ to 14.9$)$ & 11.6 (9.8 to 13.6$)$ & 1.31 (1.10 to 1.58$)$ & $1.11(0.92$ to 1.35$)$ & \\
\hline Negative & 5590 & $9.8(8.7$ to 11.0$)$ & $10.4(9.2$ to 11.8$)$ & ref & ref & \\
\hline Time since HIV diagnosis & & & & & & $<0.0001$ \\
\hline Less than 5 years & 1866 & 5.4 (3.9 to 6.9$)$ & $7.0(5.3$ to 9.1$)$ & ref & ref & \\
\hline $5-9$ years & 1932 & 8.6 (7.0 to 10.2$)$ & $9.8(8.1$ to 11.8$)$ & 1.59 (1.22 to 2.08$)$ & $1.41(1.06$ to 1.87$)$ & \\
\hline 10 or more years & 4806 & $12.9(11.6$ to 14.2$)$ & $12.3(11.1$ to 13.5$)$ & $2.40(1.88$ to 3.05$)$ & 1.77 (1.38 to 2.27$)$ & \\
\hline AIDS/nadir CD4 count in cells $/ \mathrm{mm}^{3}$ & & & & & & 0.3 \\
\hline AIDS or nadir CD4 0-199 & 5952 & $10.8(9.7$ to 11.8$)$ & $10.5(9.5$ to 11.6$)$ & 1.27 (1.08 to 1.52$)$ & 1.01 (0.83 to 1.22$)$ & \\
\hline No AIDS and nadir CD4 200-500 & 2098 & $8.5(6.5$ to 10.4$)$ & $10.4(8.6$ to 12.6$)$ & ref & ref & \\
\hline No AIDS and nadir CD4 $>500$ & 540 & $11.2(8.0$ to 14.3$)$ & $13.5(9.6$ to 18.6$)$ & 1.32 (0.97 to 1.79$)$ & $1.29(0.94$ to 1.78$)$ & \\
\hline Geometric mean CD4 past 12 months & & & & & & 0.0007 \\
\hline $0-199$ cells $/ \mathrm{mm}^{3}$ & 1118 & 9.8 (7.8 to 11.8$)$ & 10.1 (7.9 to 12.7$)$ & 1.11 (0.87 to 1.40$)$ & $1.14(0.88$ to 1.47$)$ & \\
\hline $200-349$ cells $/ \mathrm{mm}^{3}$ & 1486 & $9.8(7.9$ to 11.7$)$ & 11.4 (9.5 to 13.7$)$ & $1.11(0.89$ to 1.37$)$ & $1.29(1.05$ to 1.59$)$ & \\
\hline $350-499$ cells $/ \mathrm{mm}^{3}$ & 1949 & $8.9(7.8$ to 10.0$)$ & $8.8(7.7$ to 10.1$)$ & ref & ref & \\
\hline$\geq 500$ cells $/ \mathrm{mm}^{3}$ & 3739 & $11.3(9.8$ to 12.8$)$ & 11.5 (10.1 to 13.2$)$ & $1.27(1.13$ to 1.90$)$ & $1.30(1.14$ to 1.50$)$ & \\
\hline Prescribed ART & & & & & & 0.054 \\
\hline No & 828 & $7.2(5.1$ to 9.4$)$ & $8.3(6.2$ to 10.9$)$ & Ref & Ref & \\
\hline Yes & 7751 & 10.6 (9.5 to 11.7$)$ & $10.9(9.8$ to 12.1$)$ & $1.47(1.13$ to 1.90$)$ & $1.32(0.99$ to 1.76$)$ & \\
\hline
\end{tabular}


providers should follow existing DM screening guidelines, which recommend FBG and HbAlc be obtained prior to and after starting ART. ${ }^{37}$ Second, existing data from prospective studies should be examined to determine if screening guidelines should be modified, given the increased prevalence of DM among younger and non-obese HIV-infected persons. Third, improved tests for DM diagnosis and monitoring among HIV-infected persons should be explored, given studies that have demonstrated the diagnostic limitations of HbAlc in this population. ${ }^{10} 14 \quad 15$ Finally, additional research will be important to identify optimal DM management strategies among HIV-infected persons as traditional strategies to improve insulin sensitivity such as weight loss and diabetic medical therapy have been shown to be less effective among HIV-infected individuals. ${ }^{38} 39$

This analysis is subject to several limitations. First, the definition of diagnosed DM was different between MMP (medical record abstraction) and NHANES (selfreported) and may be a source of bias. A recent cohortbased validation of prevalence of DM based on self-report showed a specificity and negative predictive value $>95 \%$, with a sensitivity and positive predictive value between $60 \%$ and $70 \% .{ }^{40}$ This indicates that were there a bias introduced by self-reporting of DM, it would be towards and increased prevalence of DM with self-report. Furthermore, comparisons between self-reported and medical record-based estimates of DM have shown substantial agreement between both measures, and in some cases, an underestimation of DM prevalence in medical records relative to self-report. ${ }^{41-43}$ Second, there is a risk of observer bias in our sample, given differences in engagement in care between our samples. We addressed this by performing a sensitivity analysis restricting the NHANES sample to adults having received care in the previous 12 months. Although we observed only slight changes in the magnitude of the associations, there is a possibility of overestimation of the PD between MMP and NHANES. Third, risk factors for DM, such as family history/genetics, diet, and exercise, were not included in this analysis and could explain some of the excess prevalence observed among HIV-infected adults. However, the inclusion of patients with type 1 diabetes is unlikely to have resulted in the excess diabetes prevalence observed in our study as the prevalence of type 1 diabetes in NHANES has been estimated to range between $3.6 \%$ and $4.8 \% .{ }^{44}$ Fourth, the measurement of BMI and HCV were standardized for the NHANES population and not for MMP participants resulting in a biased association between these variables and DM when comparing NHANES and MMP participants. Fifth, MMP data are representative of HIV-infected persons receiving medical care and do not necessarily reflect DM prevalence among HIV-infected persons not diagnosed or not receiving care. Sixth, the increased prevalence of DM among HIV-infected women relative to the general US adult population may be due to misclassification bias; although we excluded pregnant women and diagnoses labeled gestational diabetes in the medical record of MMP participants, female patients with gestational diabetes may have been mislabeled and included in our sample. Finally, the NHANES population included HIV-infected adults who may or may not have received medical care. However, the prevalence of HIV-infected individuals in the NHANES population is negligible $(0.21 \%) .{ }^{45}$ Although diabetes rates were standardized to the combined population of MMP and NHANES, given the very small percentage represented by MMP in the general US adult population, the bias introduced should be minimal.

\section{CONCLUSION}

We presented the first nationally representative estimate of DM prevalence among HIV-infected adults receiving medical care in the USA in 2009-2010 where 1 in 10 HIV-infected adults had a diagnosis of DM. Although obesity is a risk factor for prevalent DM among HIV-infected adults, when compared with the general US adult population, HIV-infected adults may have higher DM prevalence at younger ages and in the absence of obesity. Healthcare providers caring for HIV-infected patients should follow existing DM screening guidelines. Given the large burden of DM among HIV-infected adults, additional research would help to determine whether DM screening guidelines should be modified to include HIV infection as a risk factor for DM and to identify optimal management strategies in this population.

Acknowledgements The authors thank all MMP and NHANES participants and staff members for their time and efforts. The authors also thank Dr. Emma Frazier for MMP data analytic support.

Contributors ACH-R, SG, and JS had full access to all the data in the study and take responsibility for the integrity of the data and the accuracy of the data analysis. ACH-R, SG, ESR, and JS are responsible for study concept and design, analysis and interpretation of data, drafting of the manuscript, and statistical analysis. ACH-R, SG, and JS are responsible for acquisition of data. All authors contributed to critical revision of the manuscript for important intellectual content. JS obtained funding. SG and JS are responsible for administrative, technical, and material support and study supervision.

Funding This work was supported and funded by CDC through a Cooperative Agreement (PS09-937) with MMP participating areas.

Disclaimer The findings and conclusions in this report are those of the authors and do not necessarily represent the views of the CDC.

Competing interests None declared.

Provenance and peer review Not commissioned; externally peer reviewed.

Data sharing statement NHANES additional data include biometric, social, and demographic characteristics, and data sets are available to the general public through the Centers for Disease Control and Prevention website. MMP additional data include biometric, social, behavioral, and demographic data and are only available to Centers for Disease Control and Prevention employed in the Clinical and Behavioral Branches of domestic HIV surveillance.

Open Access This is an Open Access article distributed in accordance with the Creative Commons Attribution Non Commercial (CC BY-NC 4.0) license, which permits others to distribute, remix, adapt, build upon this work noncommercially, and license their derivative works on different terms, provided the original work is properly cited and the use is non-commercial. See: http:// creativecommons.org/licenses/by-nc/4.0/ 


\section{REFERENCES}

1. Centers for Disease Control and Prevention. National Diabetes Statistics Report: estimates of diabetes and its burden in the Unites States. Atlanta, GA: US Departments of Health and Human Services, 2014.

2. Nathan DM. Long-term complications of diabetes mellitus. $\mathrm{N}$ Engl J Med 1993;328:1676-85.

3. Seshasai SR, Kaptoge S, Thompson A, et al. Diabetes mellitus, fasting glucose, and risk of cause-specific death. $N$ Engl J Med 2011;364:829-41.

4. Economic costs of diabetes in the U.S. in 2012. Diabetes Care 2013;36:1033-46.

5. Smith C, Sabin CA, Lundgren JD, et al. Factors associated with specific causes of death amongst HIV-positive individuals in the D:A D Study. AIDS 2010;24:1537-48.

6. Nakagawa F, Lodwick RK, Smith CJ, et al. Projected life expectancy of people with HIV according to timing of diagnosis. AIDS 2012;26:335-43.

7. Buchacz K, Baker RK, Palella FJ Jr, et al. Disparities in prevalence of key chronic diseases by gender and race/ethnicity among antiretroviral-treated HIV-infected adults in the US. Antivir Ther (Lond) 2013;18:65-75.

8. Brown TT, Cole SR, Li X, et al. Antiretroviral therapy and the prevalence and incidence of diabetes mellitus in the multicenter AIDS cohort study. Arch Intern Med 2005;165:1179-84.

9. Rasmussen LD, Mathiesen ER, Kronborg G, et al. Risk of diabetes mellitus in persons with and without HIV: a Danish nationwide population-based cohort study. PLoS ONE 2012;7:12.

10. Tien PC, Schneider MF, Cox C, et al. Association of HIV infection with incident diabetes mellitus: impact of using hemoglobin A1C as a criterion for diabetes. J Acquir Immune Defic Syndr 2012;61:334-40.

11. Tripathi A, Liese AD, Jerrell JM, et al. Incidence of diabetes mellitus in a population-based cohort of HIV-infected and non-HIV-infected persons: the impact of clinical and therapeutic factors over time. Diabet Med 2014;31:1185-93.

12. Frankel MR, McNaghten A, Shapiro MF, et al. A probability sample for monitoring the HIV-infected population in care in the U.S. and in selected states. Open AIDS J 2012;6:67-76.

13. Centers for Disease Control and Prevention. National Health and Nutrition Examination Survey: Survey Methods and Analytic Guidelines 2014 (cited 8 March 2015). http://www.cdc.gov/nchs/ nhanes/survey_methods.htm

14. Eckhardt BJ, Holzman RS, Kwan CK, et al. Glycated Hemoglobin $\mathrm{A}(1 \mathrm{c})$ as screening for diabetes mellitus in HIV-infected individuals. AIDS Patient Care STDS 2012;26:197-201.

15. Slama L, Palella FJ Jr, Abraham AG, et al. Inaccuracy of haemoglobin A1c among HIV-infected men: effects of CD4 cell count, antiretroviral therapies and haematological parameters. J Antimicrob Chemother 2014;69:3360-7.

16. Thompson-Paul AM, Wei SC, Mattson CL, et al. Obesity among HIV-infected adults receiving medical care in the United States: data from the cross-sectional Medical Monitoring Project and National Health and Nutrition Examination Survey. Medicine (Baltimore) 2015;94:e1081.

17. Schneider E, Whitmore S, Glynn KM, et al. Revised surveillance case definitions for HIV infection among adults, adolescents, and children aged $<18$ months and for HIV infection and AIDS among children aged 18 months to $<13$ years-United States, 2008. MMWR Recomm Rep 2008;57(RR-10):1-12.

18. Ghany MG, Strader DB, Thomas DL, et al. Diagnosis, management, and treatment of hepatitis $\mathrm{C}$ : an update. Hepatology 2009:49:1335-74.

19. Bieler GS, Brown GG, Williams RL, et al. Estimating model-adjusted risks, risk differences, and risk ratios from complex survey data. Am J Epidemiol 2010;171:618-23.

20. Muller CJ, MacLehose RF. Estimating predicted probabilities from logistic regression: different methods correspond to different target populations. Int J Epidemiol 2014;43:962-70.

21. Korn EL, Graubard BI. Analysis of health surveys. New York, NY: Wiley and Sons, 1999.

22. Gregg EW, Cheng YJ, Cadwell BL, et al. Secular trends in cardiovascular disease risk factors according to body mass index in US adults. JAMA 2005;293:1868-74.

23. De Wit $S$, Sabin CA, Weber R, et al. Incidence and risk factors for new-onset diabetes in HIV-infected patients: the Data Collection on
Adverse Events of Anti-HIV Drugs (D:A:D) study. Diabetes Care 2008;31:1224-9.

24. Freiberg MS, Chang CC, Kuller LH, et al. HIV infection and the risk of acute myocardial infarction. JAMA Intern Med 2013;173:614-22.

25. Glass TR, Ungsedhapand C, Wolbers M, et al. Prevalence of risk factors for cardiovascular disease in HIV-infected patients over time: the Swiss HIV Cohort Study. HIV Med 2006;7:404-10.

26. Capeau J, Bouteloup V, Katlama C, et al. Ten-year diabetes incidence in 1046 HIV-infected patients started on a combination antiretroviral treatment. AIDS 2012;26:303-14.

27. Guaraldi G, Orlando G, Zona S, et al. Premature age-related comorbidities among HIV-infected persons compared with the general population. Clin Infect Dis 2011;53:1120-6.

28. Betene ADC, De Wit S, Neuhaus J, et al. Interleukin-6, high sensitivity C-reactive protein, and the development of type 2 diabetes among HIV-positive patients taking antiretroviral therapy. $J$ Acquir Immune Defic Syndr 2014;67:538-46.

29. Brown TT, Tassiopoulos K, Bosch RJ, et al. Association between systemic inflammation and incident diabetes in HIV-infected patients after initiation of antiretroviral therapy. Diabetes Care 2010;33:2244-9.

30. McComsey GA, Kitch D, Sax PE, et al. Associations of inflammatory markers with AIDS and non-AIDS clinical events after initiation of antiretroviral therapy: AIDS clinical trials group A5224s, a substudy of ACTG A5202. J Acquir Immune Defic Syndr 2014;65:167-74.

31. Brown TT, Tassioppoulos K, Bosch RJ, et al. Association between systemic inflammation and incident diabetes in HIV-infected patients after initiation of antiretroviral therapy. Diabetes Care 2010;33:2244-9.

32. Ghislain M, Bastard JP, Meyer L, et al. Late Antiretroviral Therapy (ART) initiation is associated with long-term persistence of systemic inflammation and metabolic abnormalities. PLOS ONE 2015;10: e0144317.

33. Frasco MA, Karim R, Van Den Berg D, et al. Antiretroviral therapy modifies the genetic effect of known type 2 diabetes-associated risk variants in HIV-infected women. AIDS 2014;28:1815-23.

34. White DL, Ratziu V, El-Serag HB. Hepatitis C infection and risk of diabetes: a systematic review and meta-analysis. $J$ Hepatol 2008;49:831-44.

35. Holmberg SD, Spradling PR, Moorman AC, et al. Hepatitis $C$ in the United States. N Engl J Med 2013;368:1859-61.

36. Kowdley KV, Lawitz E, Poordad F, et al. Phase $2 b$ trial of interferon-free therapy for hepatitis $\mathrm{C}$ virus genotype 1. N Engl J Med 2014;370:222-32.

37. Aberg JA, Gallant JE, Ghanem KG, et al. Primary care guidelines for the management of persons infected with HIV: 2013 update by the HIV Medicine Association of the Infectious Diseases Society of America. Clin Infect Dis 2014;58:1-10.

38. Reeds DC, Patterson WT, Overton BW, et al. Metabolic benefits of weight loss are blunted in obese, HIV-infected women. Obesity 2011;19(Suppl 1):S112.

39. Han JH, Crane HM, Bellamy SL, et al. HIV infection and glycemic response to newly initiated diabetic medical therapy. AIDS 2012;26:2087-95.

40. Schneider ALC, Pankow JS, Heiss G, et al. Validity and reliability of self-reported diabetes in the atherosclerosis risk in communities study. Am J Epidemiol 2012;176:738-43.

41. Okura Y, Urban LH, Mahoney DW, et al. Agreement between self-report questionnaires and medical record data was substantial for diabetes, hypertension, myocardial infarction and stroke but not for heart failure. J Clin Epidemiol 2004;57:1096-103.

42. Corser W, Sikorskii A, Olomu A, et al. Concordance between comorbidity data from patient self-report interviews and medical record documentation. BMC Health Serv Res 2008;8:85.

43. Asao K, McEwen LN, Lee JM, et al. Ascertainment of outpatient visits by patients with diabetes: The National Ambulatory Medical Care Survey (NAMCS) and The National Hospital Ambulatory Medical Care Survey (NHAMCS). J Diabetes Complicat 2015;29:650-8.

44. Menke A, Orchard TJ, Imperatore G, et al. The prevalence of type 1 diabetes in the United States. Epidemiology 2013;24:773-4.

45. Centers for Disease Control and Prevention. National Health and Nutrition Examination Survey: Data Documentation, Codebook, and Frequencies. 2014 (cited 8 March 2015). http://wwwn.cdc.gov/nchs/ nhanes/2009-2010/HIV_F.htm 